Note: This is the text of the article prior to final editing at proofs stage.

Published in Political Insight 8, no. 3 (December 2017), pp. 24-7.

\title{
Citizens' assemblies: a better way of doing democracy?
}

There is widespread disquiet over the quality of debate surrounding Brexit - both during last year's referendum and since. But is there a better alternative? Alan Renwick reflects on lessons he learned from directing the recent Citizens' Assembly on Brexit.

The idea that we should find ways to make our democracy more deliberative is gaining momentum. Amidst concerns over 'post-truth' politics, 'fake news', and the deepening of social media echo chambers, there is a wide desire to encourage more listening across the divides and more respect for alternative perspectives.

So-called 'deliberative mini-publics' (DMPs), such as citizens' juries and citizens' assemblies, offer one promising route to achieving that. They gather together randomly selected citizens for anything from a day to several weeks. The members hear from experts and discuss in depth among themselves before reaching conclusions. Their discussions are moderated by trained facilitators to maximize the chances that everyone's voice is heard and respected and that the deliberations stay on topic. The most ambitious DMPs - large-scale citizens' assemblies in Canada, the Netherlands, and Ireland - have generated very high quality deliberation and in some cases fed into subsequent policy-making processes. There is growing evidence that DMPs, if well designed and well resourced, provide a means for bringing informed and considered public opinion to bear upon major public policy issues.

But important questions remain. Not least among these is whether DMPs work in the context of existing polarized policy debates. Several of the large-scale official citizens' assemblies have focused on electoral reform - an important topic, but not one that many citizens have strong prior views on. Many smaller-scale local DMPs have addressed matters such as how to tackle air pollution or whether to allow windfarms - issues on which some participants may have strong thoughts, but few have deeply entrenched positions.

But concerns about the state of our democracy focus mainly not on how we deal with topics such as these, but on issues where the debate has become highly polarized. It is here that we can be tempted to become 'tribal' for one side or the other, to stop listening to those we disagree with, and to succumb to the temptations of 'confirmation bias', where we mentally endorse any information or argument that fits our pre-existing views while dismissing the rest. This has clearly happened - on both sides - in the debate over Brexit, and the quality of discussion and policy-making are harmed as a result. The Citizens' Assembly on Brexit was designed in part to investigate whether a DMP can work effectively in this context too.

That raises the question of what it means for a DMP to 'work'. After briefly describing the Citizens' Assembly on Brexit, I consider the evidence that we have so far in terms of four criteria. First, is it possible to engage people in a DMP in this context? Second, can such a DMP generate internal deliberation of high quality? Third, can it yield conclusions that are consistent and meaningful? Fourth, does it affect the wider political debate and policy-making process? I write these words just a few weeks after the Citizens' Assembly on Brexit concluded, so the evidence is necessarily 
preliminary. Nevertheless, it gives good reason to be positive about the contribution that a DMP can make, even amidst high polarization.

\section{What is the Citizens' Assembly on Brexit?}

The Citizens' Assembly on Brexit is funded by the Economic and Social Research Council (ESRC) as part of its UK in a Changing Europe programme. It is led by the Constitution Unit at University College London and includes partners at the Universities of Westminster and Southampton as well as two civil society organizations: Involve (which provided professional facilitation) and the Electoral Reform Society (which led our external engagement work).

The Assembly comprised fifty people from across the UK who gathered for two weekends in Manchester during September to consider what kind of Brexit they want the UK to seek - focusing on the key issues of trade and migration. The Assembly Members were selected randomly through a 5,000-person survey administered by ICM. We contacted survey respondents who said they would like to take part in the Assembly, filling a stratification grid so that Members represented the UK electorate as closely as possible in terms of six characteristics: sex, age, ethnicity, social class, where they live, and how they voted in the referendum last year.

Each weekend ran from Friday evening until Sunday lunchtime. During the first weekend, the Members began by reflecting on the kind of country they would like to live in. They then heard from leading experts in the fields of trade and migration. Some of the experts emphasized the benefits of a clean break with the Single Market and Customs Union, others the costs. Each spoke for around ten minutes. Members then worked in small groups to consider their reactions and what questions they would like to put, and Q\&A sessions followed. Members then had further opportunities to reflect on their priorities and initial preferences.

The second weekend began on the Friday evening with talks from two MPs: Graham Brady, who spoke for leaving the Single Market and Customs Union, and Kate Green, who advocated staying in. This was the last external input to the Assembly: thereafter, the Members deliberated among themselves on what their priorities were and how, in their view, the various options would affect them. Finally, members voted on the post-Brexit arrangements that they wanted the UK to seek, relating to how we trade with the $\mathrm{EU}$, how we trade with countries beyond the $\mathrm{EU}$, migration policies, and overall Brexit packages.

\section{Did people participate?}

Our first criterion for evaluating the Assembly concerns whether people actually engaged with it. In a polarized context, the key issue here is whether there was engagement across the spectrum of views: if one side participated but the other did not, the whole exercise would be fruitless. It is necessary to recruit a membership that reflects the range of views in the electorate as accurately as possible. It is equally essential to have a diverse array of experts, and to secure campaigners on both sides who are willing to endorse the process.

The Citizens' Assembly on Brexit did very well in all these respects. Of the fifty members, twentyfive voted to leave the EU in last year's referendum, while twenty-two voted to remain and three did not vote. The Leave/Remain split thus closely mirrored that in the electorate as a whole. We clearly secured fewer non-voters than in the wider population, but we had not made representing this 
category one of our core recruitment targets. Furthermore, virtually everyone who signed up to attend did so. The figure of fifty members refers to the number who attended both weekends. Fifty-one in fact signed up, but one of these was prevented by illness from coming to the second weekend.

In addition, we secured endorsements in advance from prominent campaigners on both sides, including Bernard Jenkin and John Mills from the Leave side and Nicky Morgan and Chukka Umunna from Remain. And the experts who addressed the Assembly included people who had voted both Leave and Remain and people who advocated a wide range of approaches to Brexit.

These outcomes reflected several aspects of project design. Our ESRC funding ensured our independence from either side of the Brexit debate. We were associated with the UK in a Changing Europe programme, which, under the leadership of Professor Anand Menon, has built a strong reputation for providing impartial Brexit advice. We chose to focus the Assembly on a question that all agree is live - what form Brexit should take - rather than one that some at least perceive as settled - whether Brexit should happen. Building on these foundations, we were able to secure the endorsements noted above, and these then facilitated the further recruitment of Members and experts.

\section{Did Assembly Members deliberate effectively?}

Our second criterion concerns the quality of deliberation within the Assembly. There is little point in having members of the public sit together if they do not genuinely listen to each other. Nor is there much point in recruiting expert witnesses if the Members pay little heed to (or fail to understand) what they say. A citizens' assembly is ideally a forum for listening, learning, and reflecting, and Members should be open to changing their minds in response.

In the coming months, we will analyse transcripts of the Assembly discussions to assess deliberative quality in depth. For now, we can draw on preliminary evidence. We surveyed the Assembly Members during both weekends, asking for their perceptions of the discussions. They were extremely positive about their experience, rating the overall event highly (on average, 4.6 out of 5). They were equally positive about the balance and fairness of the information they had received (4.4) and the range of diverse opinions they had heard (4.6). They felt that they had ample opportunity to express their views (4.6) and that their fellow participants had respected what they had to say, even when they didn't agree with them (4.5).

Members believed that they had had enough information to participate effectively (4.6) and that the Assembly had helped to clarify their views about Brexit (4.4). Their perception of their understanding of the issues of trade and immigration in relation to Brexit rose significantly across the two weekends ( 3.2 at the start of the first weekend to 4.2 at the end of the second). Having completed two weekends of service, they strong agreed that citizens' assemblies should be used more often to inform government decision-making (4.8).

My own impressions having watched the Assembly members at work fit these responses. Members engaged with each other constructively across both weekends. Even during breaks and over meals, I often saw members with very different views engaged in amicable discussion.

Here the role of our facilitation team - led by Involve's Sarah Allan - was especially important. They set a tone for others to follow and worked very hard to ensure that everyone's voice was heard. We 
do not claim to have attained perfection. But our initial impression is that Members engaged across the Brexit divide even more strongly than we hoped.

\section{Did the Assembly yield consistent conclusions?}

Quality discussions are all very well, but it is the conclusions of the Assembly that the outside world wants to hear. These conclusions cannot be evaluated in terms of whether they are 'right' or 'wrong': there is legitimate disagreement over what form of Brexit might be best. But we can consider whether they are internally consistent and reflect the tenor of the discussions that preceded them.

In fact, the Assembly's conclusions were highly consistent. Most members repeatedly endorsed what has come to be known as a 'soft' Brexit. They wanted the UK to strike a bespoke trade deal with the EU that would facilitate a high level of free trade between the UK and the EU and avoid any need for physical customs checks on the UK/EU border. Should such a deal prove unattainable, they would prefer the UK to stay in the Single Market and the Customs Union than to leave the EU with no deal. Perhaps surprisingly, given the general tone of public debate, they wanted free movement of labour between the UK and the EU to continue, but said the UK should use all available controls and take other policy measures to limit the level of immigration. When we asked Members to consider overall Brexit packages, their conclusions closely mirrored these segmented decisions.

We will be able to comment on how Members reached these conclusions in greater detail once we have analysed the transcripts. It is our clear impression, however, that they had genuinely reflected on their own priorities and on the evidence they had heard about the effects of the various options, and that their conclusions were consistent with these.

\section{Will the Citizens' Assembly affect the wider policy debate?}

It is too early to offer any confident assessment in relation to our final question. On the positive side, the Assembly has received much interest in the Twittersphere, and James Blitz, writing in the Financial Times immediately after the second weekend, observed: "If democracy is to work well, public opinion needs to be properly informed... On an issue as complex as Brexit, people need more citizens' assemblies to cut through the cacophony." In addition, by the time of writing, my colleagues and I had been invited to give evidence on the Citizens' Assembly's workings and conclusions before two parliamentary select committees. On the more negative side, media attention has been limited. There is also a danger that the Assembly might simply be used by politicians and campaigners to advance their own agendas, rather than taken for what it is: a fresh source of evidence on informed and considered public opinion that deserves careful attention from all.

Our hope is that, as the Brexit process continues, the voice of the Citizens' Assembly will receive that careful attention. Whether that is the case only time can tell.

\section{Conclusion}

The Citizens' Assembly on Brexit has deepened our understanding of public opinion towards Brexit. It also adds to the growing body of evidence that deliberative mini-publics can contribute positively 
to debates over important - and also contentious - policy questions. My colleagues and I will be working hard over the coming months to spread this message as widely as we can.

Dr Alan Renwick is Deputy Director of the Constitution Unit at University College London and Principle Investigator for the Citizens' Assembly on Brexit. 